\title{
CENÁRIOS DE MUDANÇAS CLIMÁTICAS PROJETADOS PARA O ESTADO DE MINAS GERAIS
}

\author{
REBOITA, Michelle Simões - reboita@gmail.com \\ Universidade Federal de Itajubá / UNIFEI
}

\author{
MARRAFON, Vitor Hugo de Almeida - vitor-h.a@hotmail.com \\ Universidade Federal de Itajubá / UNIFEI
}

\author{
LLOPART, Marta - marta@fc.unesp.br \\ Universidade Estadual Paulista Júlio de Mesquita Filho / UNESP \\ Instituto de Pesquisas Meteorológicas (IPMet)
}

\author{
DA ROCHA, Rosmeri Porfírio - rosmerir@model.iag.usp.br \\ Universidade de São Paulo / USP
}

\begin{abstract}
RESUMO: O Estado de Minas Gerais está inserido numa região de clima de monção, o que significa que mais da metade do total anual da precipitação ocorre entre a primavera e o outono do ano seguinte. Portanto, essa época é a mais propícia à ocorrência de eventos extremos de precipitação. Uma vez que episódios de chuva intensa ou grandes sequências de dias com ou sem chuva podem causar danos a vários setores da economia (agrícola, energético, turístico etc.), o objetivo do presente estudo é analisar projeções futuras de precipitação e temperatura do ar no Estado de Minas Gerais, com base em três simulações climáticas realizadas com o Regional Climate Model version 4 (RegCM4). O período histórico corresponde aos anos de 1980-2005 e o futuro aos de 2070-2095. Para esse último, é considerado o cenário de mudanças climáticas Representative Concentration Pathways 8.5 (RCP8.5) do Painel Intergovernamental de Mudanças Climáticas (IPCC). Para a precipitação, foram analisados índices climáticos relacionados a valores médios e extremos. Já para a temperatura do ar apenas analisaram-se os valores médios. Entre os resultados têm-se que a temperatura do ar poderá aumentar em até 5 ${ }^{\circ} \mathrm{C}$ no Estado, enquanto a precipitação mostra uma tendência de aumento no verão e redução no inverno. As projeções climáticas também indicam que, para o final do século, a sequência de dias consecutivos úmidos tende a reduzir, enquanto a de dias secos a aumentar
\end{abstract}

PALAVRAS-CHAVE: mudanças climáticas, Minas Gerais, temperatura do ar, precipitação, eventos extremos

\section{CLIMATE CHANGE SCENARIOS PROJECTED TO MINAS GERAIS STATE}

ABSTRACT: Minas Gerais state is located in a region of monsoon climate. It means that more than half of the annual total of precipitation occurs between the spring and autumn of the next year. Therefore, this is the more favorable period for the occurrence of precipitation extreme events. Since events of intense rain or dry and wet spells can cause problems for several sectors (agriculture, energy, tourism etc.), the purpose of this study is to analyze the climate projections of the air temperature and precipitation over the Minas Gerais state, based on three climate simulations carried out with the Regional Climate Model version 4 (RegCM4). The historic period is represented by the years 19802005 and the future, 2070-2095. To the future, it is considered the Representative Concentration Pathways 8.5 (RCP8.5) scenario of climate change from Intergovernmental Panel on Climate Change (IPCC). For precipitation, we analyzed the climate indices related to the mean and extreme values. For the air temperature, we only analyzed the mean values. Among the results, it is shown that the air temperature can increase until 5 ${ }^{\circ} \mathrm{C}$ in the future, while the precipitation shows a positive (negative) trend in summer 
(winter). The climate projections also indicate a decrease of wet spells and an increase of dry spells in Minas Gerais

KEYWORDS: climate change, Minas Gerais state, air temperature, precipitation, extreme events

\section{INTRODUÇÃO}

O sistema climático terrestre responde à interação entre seus componentes, que são: a atmosfera, hidrosfera, criosfera, biosfera e litosfera (IPCC, 2007). Perturbações em um dos componentes, consequentemente, afetará todo o sistema climático. As perturbações podem ser decorrentes de fatores naturais ou antrópicos. Com relação aos fatores antrópicos, têm-se as mudanças induzidas pelo homem na composição química da atmosfera, notadamente, a liberação de gases de efeito estufa. Embora o efeito estufa seja um fenômeno natural do planeta, ele se intensifica pela maior concentração de certos gases na atmosfera como o dióxido de carbono, metano e óxido nitroso, por exemplo. Considerando o excesso desses gases na atmosfera, a radiação terrestre que deveria ser emitida para o espaço é aprisionada por esses gases e reemitida para a superfície do planeta (efeito estufa) contribuindo para o aumento das temperaturas. Com isso, ocorre um efeito de retroalimentação: em um clima mais quente há mais evaporação e, como o vapor d'água também é um gás de efeito estufa, irá contribuir ainda mais para o aumento das temperaturas do planeta.

Uma maneira de mostrar a influência humana no clima é através de experimentos com modelos numéricos. Os relatórios do Painel Intergovernamental sobre Mudanças Climáticas (Intergovernmental Panel on Climate Change - IPCC, 2007, 2013) têm mostrado que o aumento registrado na temperatura do ar global nas últimas décadas não é reproduzido pelos modelos sem a inserção da componente antrópica (como mostrado, por exemplo, na figura 10.21 do IPCC, 2013). Os modelos numéricos climáticos são constituídos por equações que representam os processos físicos da natureza (YNOUE et al., 2017). De maneira breve, há um modelo para cada componente do sistema climático, porém o acoplamento entre eles ainda é alvo de estudos e melhorias. Basicamente, o clima é simulado e projetado com modelos de circulação atmosférica (componente atmosférica). Existem dois tipos de modelos: os globais e os regionais (também chamados de modelos de área limitada). Os modelos globais simulam o clima de todo o planeta, enquanto os regionais, apenas de áreas limitadas. Entretanto, como os modelos globais são executados com espaçamento de grade de cerca de $100 \mathrm{~km}$ (latitude por longitude), eles não conseguem capturar as características regionais do clima que são influenciadas, por exemplo, pela topografia. Esses modelos não são executados com melhor resolução horizontal, pois ainda não possuem representação adequada (em alta resolução) de alguns processos físicos da natureza e também porque seriam necessários muita capacidade computacional e espaço para armazenamento dos dados simulados. Por esses motivo, são utilizados os modelos de área limitada (AMBRIZZI et al., 2018), que podem representar de forma mais realística o clima local (GIORGI e MEARNS, 1999).

Os modelos climáticos são utilizados tanto para o estudo de processos físicos no clima presente como para projetar o clima futuro (AMBRIZZI et al., 2018). Antes de se realizar estudos para o clima futuro, a performance dos modelos climáticos é avaliada através da realização de simulações para o clima presente que são comparadas com dados observados. Só após essa análise é 
que os modelos são utilizados para projetar o clima futuro. Além disso, para a projeção (nome utilizado para designar resultados de modelos numéricos para o futuro) do clima futuro são necessários cenários, que são suposições sobre as atividades humanas e efeitos naturais no futuro. Para o último relatório do IPCC (2013), foram desenvolvidos quatro cenários chamados de Representative Concentration Pathways (RCPs; VAN VUUREN et al., 2011): RCP2.6, RCP4.5, RCP6 e RCP8.5. Os números que acompanham as siglas indicam a forçante radiativa, que é uma perturbação no equilíbrio energético do planeta e, em geral, é expressa em $\mathrm{W} \mathrm{m}^{-2}$. Por exemplo, no cenário RCP2.6, projeta-se um aumento da temperatura do ar de cerca de $2{ }^{\circ} \mathrm{C}$ comparada ao período préindustrial, o que significa que a forçante radiativa atinge $3 \mathrm{~W} \mathrm{~m}^{-2}$ antes de 2100 sendo seguida por uma redução em seu valor. O RCP8.5 é o cenário mais pessimista, em que a temperatura global pode aumentar até $8{ }^{\circ} \mathrm{C}$ quando comparada aos valores pré-industriais.

É importante mencionar que as mudanças no clima não ocorrem de maneira homogênea no planeta. Tem sido reportado pelo IPCC $(2007,2013)$ a ocorrência de eventos extremos (secas, enchentes, ondas de calor e de frio, tempestades etc.) mais recorrentes e intensos nas últimas décadas e que podem estar relacionados às alterações climáticas. Com relação à América do Sul, eventos de seca na Amazônia foram registrados em 1997/1998, 2005 e 2010 (MARENGO et al., 2008, 2011) e, no sudeste do Brasil, em 2001 e 2014 (COELHO ET AL., 2015). Em 2004, a costa sul do Brasil foi afetada pelo primeiro furacão documentado no oceano Atlântico Sul, o Catarina (McTAGGART-COWAN et al., 2005; IWABE et al., 2011). Os eventos extremos afetam diretamente a disponibilidade hídrica, o setor energético, a agricultura entre outros.

Como as mudanças no clima causam impactos e/ou vulnerabilidades em praticamente todas as atividades humanas, é de grande interesse dos tomadores de decisão a informação sobre projeções climáticas. Por exemplo, para o Estado de Minas Gerais (MG), essas informações são de grande valia para a agricultura, já que o Estado tem destaque principalmente na produção do café, sendo responsável por $70,8 \%$ da produção total do país (LSPA-IBGE, 2017). Considerando um aumento de $5,8^{\circ} \mathrm{C}$ na temperatura do ar e redução de $15 \%$ na precipitação em MG, Asaad et al. (2004) indicaram que somente o extremo sul do Estado teria condições para o cultivo do café. Isso, portanto, impactaria grandemente a economia mineira. Santos et al. (2017) realizaram um estudo similar, mas para o cultivo de oliveira em MG utilizando modelos climáticos globais do IPCC e os quatros cenários RCPs. No clima atual, 37\% de área do Estado é apta, $15 \%$ é área marginal e $48 \%$ é área inapta ao cultivo de oliveira. Para o período de 2071-2100 e considerando o cenário RCP8.5 apenas $4 \%$ da área é classificada como apta, 6\% como marginal e 90\% como inapta.

Em termos das características climáticas de MG, este Estado insere-se no regime de Monção da América do Sul, o que indica que a maior parte da precipitação ocorre durante meados da primavera a meados do outono do ano seguinte (SILVA e REBOITA, 2014; REBOITA et al., 2015). Portanto, esse é o período mais propício a eventos extremos de precipitação. Além disso, devido à topografia complexa de MG, com as serras do Espinhaço e da Mantiqueira, há a formação de circulações locais que influenciam o clima local (CAMPOS et al., 2016; OLIVEIRA et al., 2018). Estudos para MG têm avaliado a tendência da temperatura do ar e precipitação em séries históricas, bem como a tendência de eventos extremos dessas variáveis, e também utilizado modelos climáticos globais para projetar o futuro climático do Estado. Salviano et al. (2016), 
analisando as tendências de precipitação e temperatura no Brasil, entre 1961 a 2001, com dados do Climatic Research Unit (CRU), mostraram que MG possui tendência positiva e estatisticamente significativa na temperatura média em todos os meses do ano, enquanto que a precipitação é mais variável, isto é, há tendência positiva e significativa em todo o Estado no mês de março e restrita ao centro-sul em setembro e dezembro. Nos demais meses, não há tendências significativas na precipitação. Ávila et al. (2014) determinaram as tendências das temperaturas mínima e máxima em 43 municípios de MG, com período de 30 anos, obtidas das estações meteorológicas do Instituto Nacional de Meteorologia (INMET). Foram analisados os meses de janeiro, abril, julho e outubro, por representarem os meses centrais de verão, outono, inverno e primavera, respectivamente. Em geral, há predomínio de tendências positivas e estatisticamente significativas das temperaturas mínima e máxima, sendo a tendência mais acentuada em outubro. Tendência negativa e significativa na temperatura mínima só foi observada em julho e, geralmente, nos municípios localizados em maior altitude.

Com relação à ocorrência de eventos extremos de precipitação em MG, Silva (2013) analisou a tendência sazonal dos extremos chuvosos acima do percentil de $90 \%$ em dados obtidos da Agência Nacional de Águas (ANA). O verão é a estação do ano com predomínio de tendências positivas e estatisticamente significativas em todo 0 Estado. Pouquíssimos locais distribuídos por MG mostraram tendência negativa nessa estação do ano. Reis et al. (2018) determinaram a frequência de eventos extremos chuvosos em MG considerando dois períodos: a estação chuvosa (outubro a março) e a seca (abril a setembro). Para tanto, utilizaram dados de 1975 a 2015 registrados em 48 estações meteorológicas do INMET. Quando um episódio de chuva diária excedeu o valor do percentil $95 \%$, foi considerado evento extremo. Foi mostrado que a frequência de eventos extremos chuvosos tem aumentado na estação úmida e diminuído na estação seca. No período chuvoso, das 48 estações meteorológicas, 43 apresentaram tendência positiva e, dessas, 20 com significância estatística. Já no período seco, as tendências negativas foram registradas em 23 estações meteorológicas.

Em termos de clima futuro, são pouquíssimos os estudos que focam MG. Natividade et al. (2017) computaram índices de extremos climáticos de temperatura e precipitação em MG, considerando o cenário RCP4.5, com base nas projeções de 19 modelos climáticos globais do Coupled Model Intercomparison Project Phase 5 (CMIP5), que é o projeto que fornece dados para o IPCC. Também foi analisado o período histórico 1948-2005, que serviu para comparação com os períodos de 2041-2070 e 2071-2100. Foi obtido aumento da frequência de dias e noites quentes (índices denominados de TX90p e TN90p) e uma redução de dias e noites frias (TX10p e TN10p), tanto no período presente quanto para o período futuro. Para os índices relacionados à precipitação, projeta-se aumento das condições secas no norte do Estado e das condições úmidas no sul deste. Darela Filho et al. (2016) também utilizaram as projeções do CMIP5, mas para computar um índice de vulnerabilidade econômica no Brasil que inclui variáveis atmosféricas e sociais. Setores ao redor da capital mineira e ao norte do Estado serão mais vulneráveis em cenários de mudanças climáticas. Por outro lado, Quintão et al. (2017) determinaram um índice de vulnerabilidade humana apenas para MG. Para isso, utilizaram as projeções do modelo climático regional Eta aninhado ao modelo global HadGEM2-ES e considerando os cenários RCP4.5 e RCP8.5. Nesse último 
cenário, foi projetado maior índice de vulnerabilidade humana nos setores sul e leste do Estado, o que diverge do estudo de Darela Filho et al. (2016). Há diversos fatores que podem contribuir para a diferença nos resultados desses autores, como as projeções climáticas que foram obtidas de diferentes modelos para cálculo dos índices e a metodologia de cada índice.

Com base no conhecimento de que: (1) os modelos climáticos regionais podem reproduzir mais adequadamente as circulações locais e, por isso, simular mais realisticamente o clima local do que os modelos climáticos globais, (2) considerando o fato de que MG é um Estado com topografia complexa e (3) que há poucos estudos com modelos climáticos regionais focando o Estado, o objetivo do presente trabalho é prover informações do futuro climático de MG através de projeções realizadas com o Regional Climate Model version 4 (RegCM4) que consideram o cenário RCP8.5 do IPCC.

\section{METODOLOGIA}

O quinto relatório do IPCC (2013) foi o primeiro a incluir informações sobre modelos climáticos regionais. Para isso, foram organizados grupos de trabalho no globo e um deles foi o Phase I Coordinated Regional Climate Downscaling Experiment Project (CORDEX; GIORGI et al., 2009). O CORDEX desenvolveu um protocolo para a realização de simulações/projeções com diferentes modelos regionais para vários domínios no globo. Diante dessa breve contextualização, o presente estudo utiliza três projeções climáticas do CREMA (CORDEX RegCM4 hyper-Matrix experiment; GIORGI et al., 2014; LLOPART et al. 2014) realizadas com o RegCM4 para o domínio da América do Sul. O RegCM4 foi aninhado a três modelos globais: Max Planck Institute for Meteorology-Earth system model (MPI-ESM-MR; GIORGETTA et al. 2012), Geophysical Fluid Dynamics Laboratory global model (GFDL-ESM2M, DUNNE et al. 2012) e Hadley Global Environment Model 2-Earth System (HadGEM2-ES; JONES et al. 2011). Para o período futuro é considerado o cenário RCP8.5. Ao longo do trabalho, as simulações são denominadas de RegMPI, RegGFDL e RegHad, respectivamente. O RegCM4 foi integrado com resolução horizontal de $\sim 50 \mathrm{~km}$ e 18 níveis verticais sigma-pressão. Com relação às parametrizações físicas, o RegMPI e RegGFDL usaram o esquema de interação superfícieatmosfera Community Land Model version CLM3.5 (TAWFIK e STEINER, 2011) e o esquema de convecção cumulus de Emanuel e Zivkovic-Rothman (1999). Já o RegHad utilizou o esquema de superfície Biosphere-Atmosphere Transfer Scheme (BATS; DICKINSON et al. 1993) e o esquema de convecção cumulus de Grell (GRELL, 1993) sobre o continente e Emanuel sobre o oceano. As simulações mencionadas já foram validadas no período presente por da Rocha et al. (2014), Llopart et al. (2014) e Reboita et al. (2017).

Serão analisadas as três projeções climáticas com o intuito de mostrar que as projeções possuem incertezas (CHEN e FRAUENFELD, 2014). Essas incertezas estão associadas, por exemplo, com o conhecimento incompleto do estado inicial e das condições de fronteira utilizadas nos modelos, desconhecimento e/ou inabilidade de representação de todos os processos envolvidos no sistema climático, suposições sobre os cenários futuros etc. (GIORGI, 2010; LATIF, 2011; GETTELMAN e ROOD, 2016). Os períodos analisados são: 1980-2005 (presente) e 2070-2095 (futuro). Para o presente também são utilizados dados observados de precipitação e temperatura do ar diários do Climate Prediction Center (CPC, CHEN et al., 2008) com resolução 
horizontal de $0,50 \times 0,50$ (aproximadamente $50 \mathrm{~km}$ ). Inicialmente é realizada uma breve comparação da temperatura do ar e precipitação observada no clima presente (1980-2005) com a das três simulações. Após são analisadas as projeções do clima futuro.

Eventos de tempo/clima com valores estatísticos atípicos, conhecidos como eventos extremos, causam impactos significativos na sociedade e nos ambientes naturais (IPCC, 2012). Esses eventos encontram-se nas caudas das distribuições estatísticas que descrevem o comportamento das variáveis atmosféricas. É de interesse realizar projeções desses eventos, pois o conhecimento da probabilidade de ocorrência dos mesmos auxilia os tomadores de decisão em estratégias de planejamento. Para isso, utilizam-se índices estabelecidos na literatura (HAYLOCK et al., 2006; WMO, 2009; SILLMANN et al., 2013a-b). No presente estudo, são computados, tanto para o presente quanto para o futuro, os índices de precipitação PRCTOT, R95p, RX5day, CWD e CDD definidos na Tabela 1. Esses índices são calculados com dados diários. Para a temperatura do ar, foram calculadas apenas a média sazonal e a diferença entre futuro e presente, que indica a tendência climática.

Após os cálculos dos índices considerando os períodos presente e futuro, foi computada a diferença "futuro menos presente" e aplicado o teste de significância estatística t-Student (TRIOLA, 2008) para verificar se as médias dos dois períodos são diferentes. Foi utilizada a significância de 0,1. 
Tabela 1- Descrição dos índices climáticos computados no estudo para o clima presente e futuro. O estudo realizado aqui é sazonal. Portanto, os valores serão determinados para cada estação do ano de todos os anos em estudo.

\begin{tabular}{|c|c|c|c|c|}
\hline Sigla & $\begin{array}{l}\text { Nome do } \\
\text { Índice }\end{array}$ & Definição do Índice & Unidade & $\begin{array}{l}\text { Período } \\
\text { que é } \\
\text { aplicado }\end{array}$ \\
\hline PRCTOT & $\begin{array}{c}\text { Total de } \\
\text { precipitação }\end{array}$ & Total de precipitação & $\mathrm{mm} / \mathrm{dia}$ & Sazonal \\
\hline R95p & $\begin{array}{l}\text { Dias muito } \\
\text { úmidos }\end{array}$ & $\begin{array}{l}\text { Pr é a precipitação diária de } \\
\text { um dia muito úmido. } \\
\text { Inicialmente são selecionados } \\
\text { os dias com } \mathrm{Pr} \geq 1 \mathrm{~mm} \text {. Após } \\
\text { é computado o percentil de } \\
95 \% \text { e, na sequência, somada } \\
\text { a precipitação dos dias que } \\
\text { mostraram valores superiores } \\
\text { ao percentil. }\end{array}$ & $\mathrm{mm} / \mathrm{dia}$ & Sazonal \\
\hline RX5day & $\begin{array}{l}\text { Precipitação } \\
\text { máxima em } \\
5 \text { dias }\end{array}$ & $\begin{array}{c}\text { Dentro de um ano, é } \\
\text { computado o máximo valor } \\
\text { acumulado (em mm) dentro } \\
\text { de um intervalo de } 5 \text { dias } \\
\text { consecutivos. De acordo com } \\
\text { Frich et al. (2002), esse índice } \\
\text { é usado para descrever } \\
\text { mudanças no risco de } \\
\text { enchentes devido a condições } \\
\text { de chuva forte numa } \\
\text { sequência de dias. }\end{array}$ & $\mathrm{mm} / \mathrm{dia}$ & Sazonal \\
\hline CWD & $\begin{array}{c}\text { Dias } \\
\text { consecutivos } \\
\text { úmidos } \\
\end{array}$ & $\begin{array}{c}\text { Maior número de dias } \\
\text { consecutivos com precipitação } \\
\text { diária }>1 \mathrm{~mm} \text {. }\end{array}$ & dias & Sazonal \\
\hline CDD & $\begin{array}{c}\text { Dias } \\
\text { consecutivos } \\
\text { secos }\end{array}$ & $\begin{array}{c}\text { Maior número de dias } \\
\text { consecutivos com precipitação } \\
\text { diária }<1 \mathrm{~mm} \text {. De acordo com } \\
\text { Sillmann et al. (2013b), esse } \\
\text { índice é um indicador de } \\
\text { secas. } \\
\end{array}$ & dias & Sazonal \\
\hline
\end{tabular}

\section{RESULTADOS}

\subsection{CLIMA PRESENTE}

Essa seção apresenta uma comparação das simulações no clima presente com os dados observados do CPC. Em MG, as maiores médias de temperatura do ar ocorrem no verão e as menores no inverno (Figura 1). As simulações reproduzem essa variabilidade sazonal, porém, são ligeiramente mais frias do que o CPC. Por exemplo, no verão, no centro sul de MG é registrado cerca de $22-24^{\circ} \mathrm{C}$ na observação (Figura 1a) enquanto as simulações indicam $20-22^{\circ} \mathrm{C}$ (Figura 1b-d). Se há viés no clima presente, esse se mantém no futuro. Portanto, quando a diferença futuro menos presente é computada tem-se apenas como resultado a tendência projetada. Em outras palavras, o viés não afeta a interpretação das projeções climáticas.

Com relação à precipitação (Figura 2 ), o CPC mostra o verão como a estação mais chuvosa do Estado e com os maiores totais distribuídos pelo 
centro-sul de MG. Padrão similar ocorre na primavera (Figura $2 \mathrm{~m}$ ), porém com totais mais reduzidos. Já, o inverno, é a estação do ano mais seca (Figura 2i). 0 RegCM4 é hábil em representar o padrão sazonal da precipitação, mas com algumas diferenças em valores. Em termos de diferenças com o CPC, tem-se que o RegGFDL e o RegHadGEM são mais secos do que o CPC no verão; mas, por outro lado, são mais úmidos no centro-sul do Estado na primavera, o que anualmente gera uma compensação. Já o RegMPI é mais úmido do que o CPC no verão. De maneira geral, as simulações representam o clima observado de MG, podendo ser utilizadas em projeções climáticas. Mais detalhes sobre a validação das três simulações podem ser obtidos em da Rocha et al. (2014), Llopart et al. (2014) e Reboita et al. (2017).
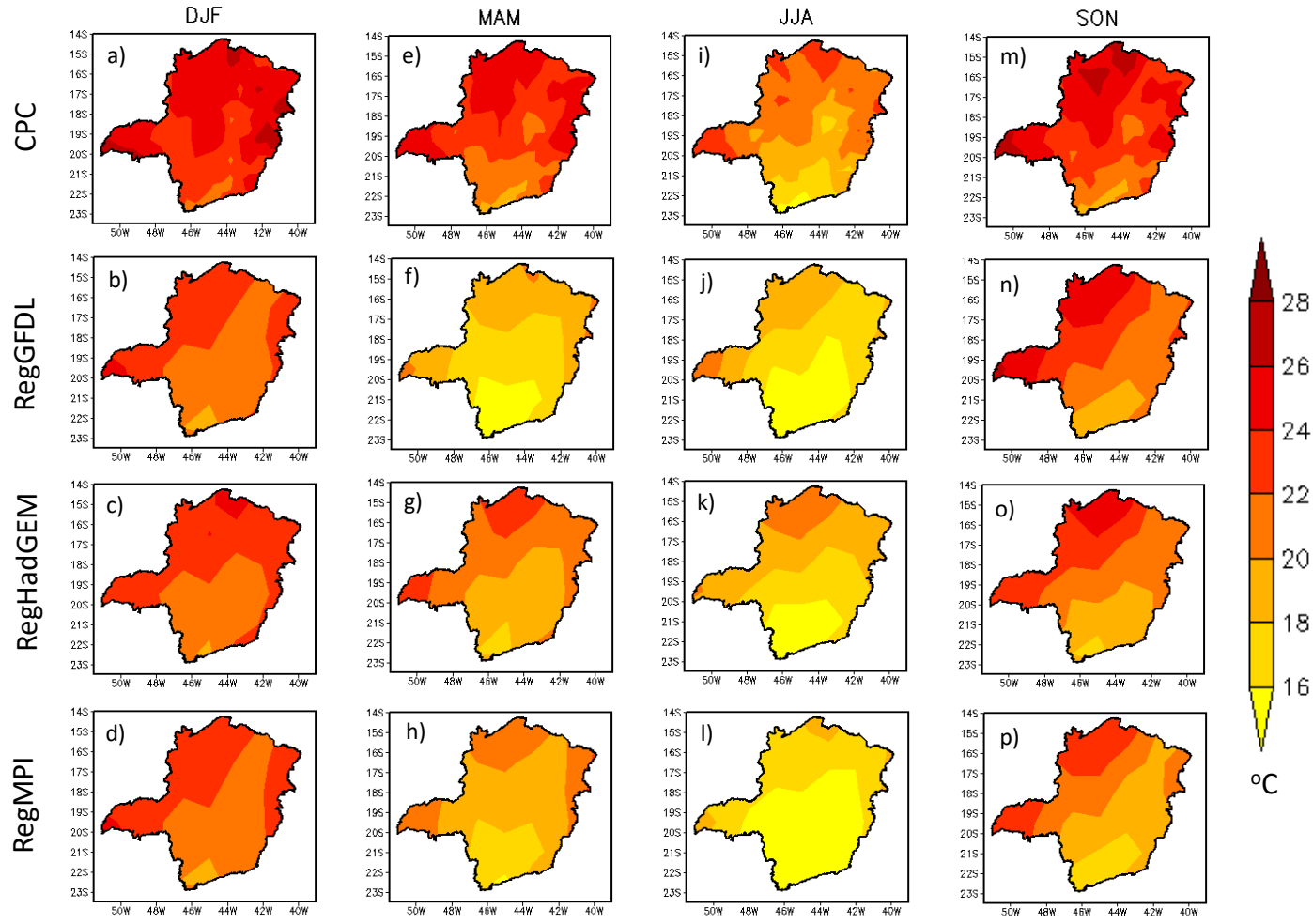

Figura 1 - Média sazonal da temperatura do ar $\left({ }^{\circ} \mathrm{C}\right)$ em MG, no período 1980 a 2005, observada pelo CPC e nas simulações RegGFDL, RegHadGEM e RegMPI. 

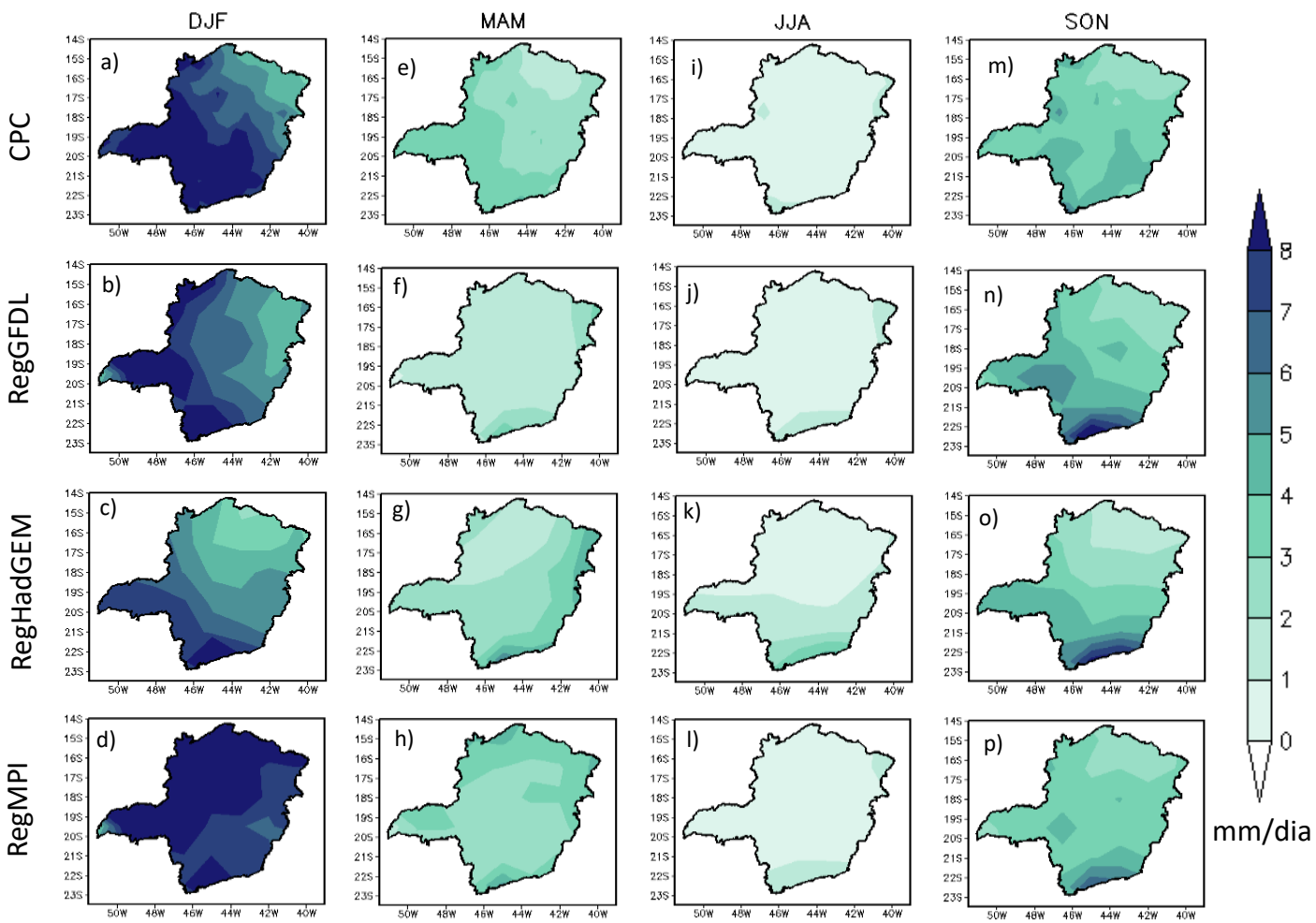

Figura 2 - Média sazonal da precipitação (mm/dia) em MG, no período 1980 a 2005, observada pelo CPC e nas simulações RegGFDL, RegHadGEM e RegMPI.

\subsection{CLIMA FUTURO}

Aqui são apresentados os resultados das projeções com base nos índices climáticos descritos na Tabela 1. Considerando a temperatura do ar, as três projeções com o RegCM4 indicam aumento estatisticamente significativo da temperatura do ar no período 2070-2095 e, em geral, há um gradiente horizontal de temperatura, indicando aumento do setor oeste para o leste do Estado (Figura 3). Esse padrão espacial também é obtido nas projeções de modelos globais mostradas por Santos et al. (2017). O aumento sazonal projetado nas temperaturas varia de $2^{\circ} \mathrm{C}$ (JJA no RegGFDL e MAM no RegMPI) a $5^{\circ} \mathrm{C}$ (na primavera no RegHadGEM e RegMPI). As estações do ano, em geral, são mais quentes no RegHadGEM.

Outra maneira de mostrar as mudanças projetadas na temperatura do ar é através do cálculo da densidade de probabilidade. Isso foi realizado para os dois períodos em estudo e considerando as três projeções (Figura 4). Para tanto, utilizou-se a média diária da temperatura do ar calculada entre as coordenadas: 23,50 e $140 \mathrm{~S}$ e 51,50 e 39o W, área que cobre todo o Estado de MG. A característica mais interessante da Figura 4 é o deslocamento para a direita das curvas referentes às projeções, o que significa que a média da temperatura é maior no período 2070-2095 comparada ao período 1980-2005. Em outras palavras, a mudança no valor médio climatológico é o que define mudanças no clima. No clima presente, a média da temperatura é $20,7{ }^{\circ} \mathrm{C}, 21,2$ ${ }^{\circ} \mathrm{C}$ e $20,4{ }^{\circ} \mathrm{C}$ no RegGFDL, RegHadGEM e RegMPI, respectivamente. Já no clima 
futuro, os valores são $23,6{ }^{\circ} \mathrm{C}, 25,8{ }^{\circ} \mathrm{C}$ e $24,0{ }^{\circ} \mathrm{C}$, respectivamente. Aqui também fica claro que o RegHadGEM é o que projeta as maiores temperaturas no futuro.
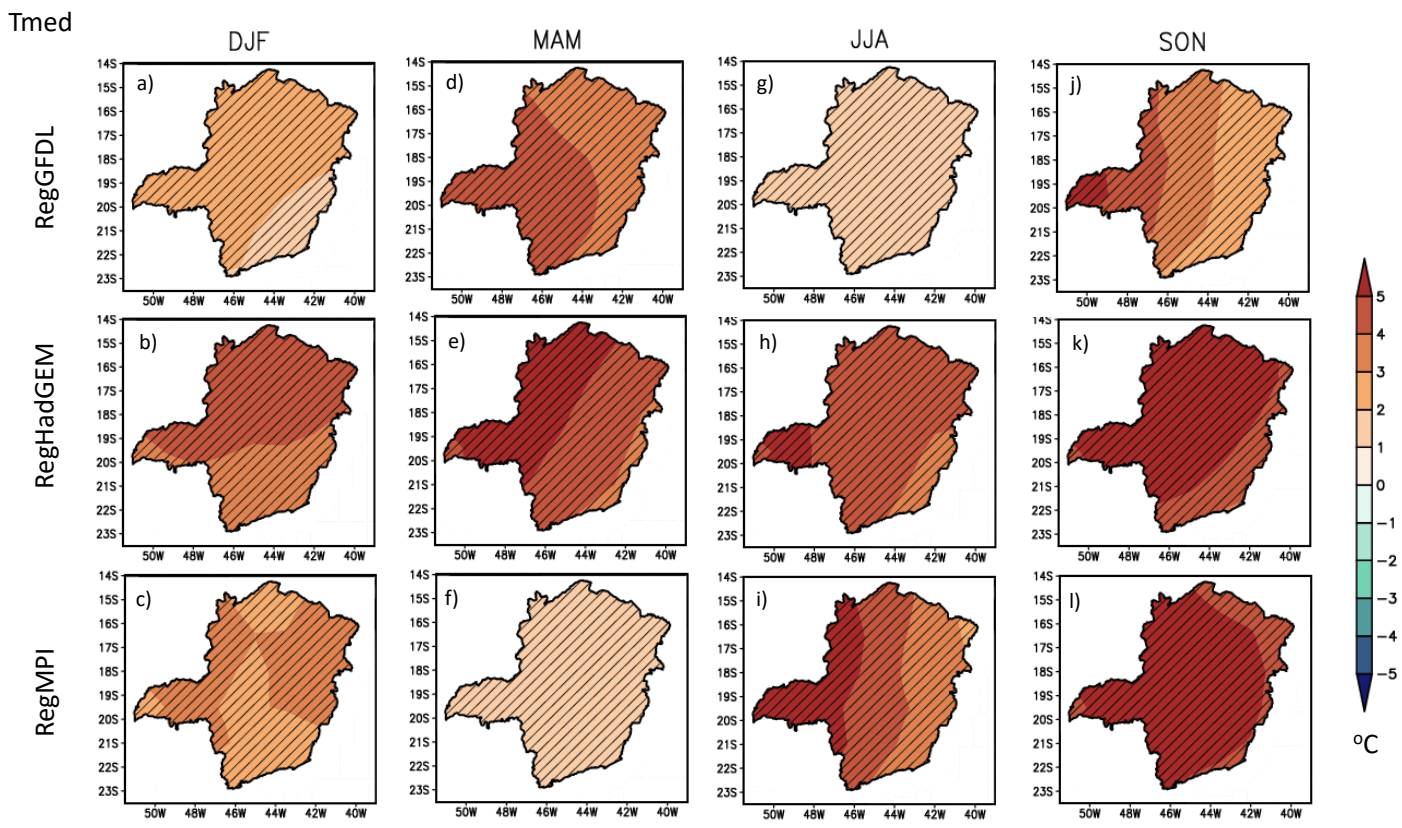

Figura 3 - Projeção sazonal da temperatura do ar (oC), futuro (2070-2095) menos presente (1980-2005), no Estado de Minas Gerais considerando o cenário RCP8.5. Regiões hachuradas indicam que há significância estatística nas diferenças com a=0,1.

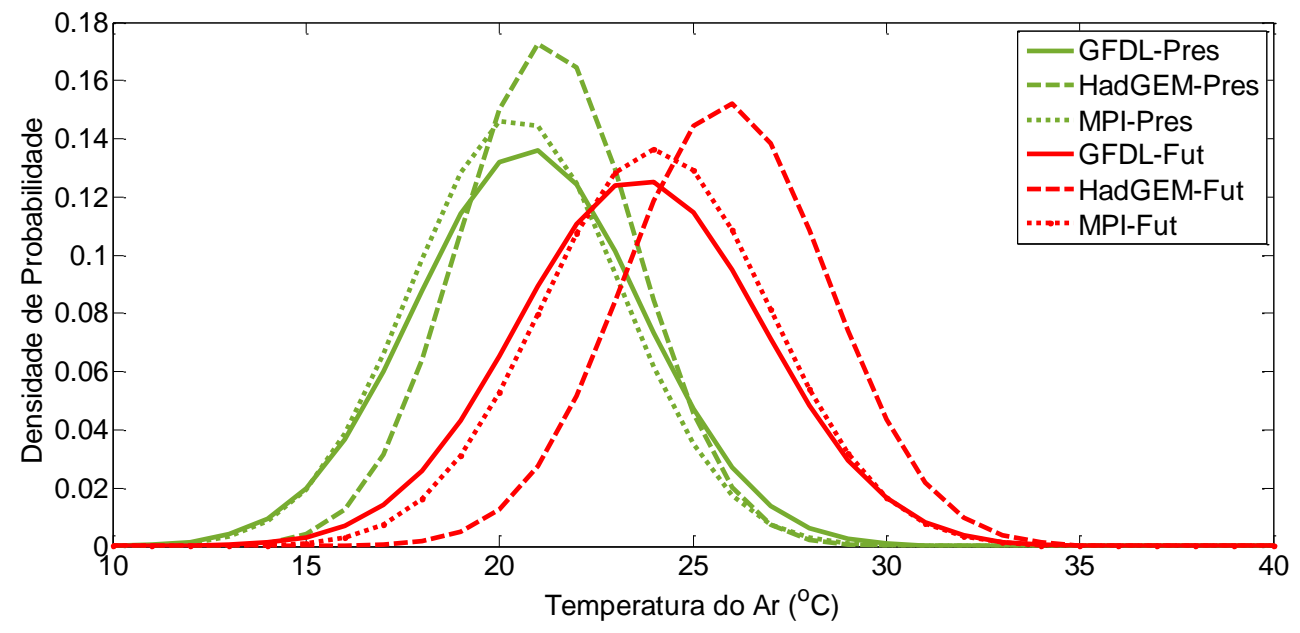

Figura 4 - Densidade de probabilidade da temperatura do ar em nos períodos 19802005 e 2070-2095 para as três projeções climáticas (ver legenda da figura).

Com relação à precipitação no clima futuro, o RegGFDL e RegHadGEM indicam aumento do volume de precipitação (PRCTOT) no verão, comparados ao presente, enquanto o RegMPI mostra essa característica na primavera (Figura 
5). Já para as demais estações do ano, as projeções indicam condições mais secas que no presente (Figura 5). O inverno é um período preocupante, pois os totais de precipitação já são baixos e poderão se tornar ainda menores (decréscimo de $1 \mathrm{~mm} /$ dia), o que pode ter consequências negativas na saúde humana. O padrão e valores sazonais projetados da precipitação na Figura 5 se assemelham com os dos modelos globais do CMIP5 (SANTOS et al., 2017) e com uma projeção do RegCM3 aninhado ao HadCM3 usando o cenário A1B (REBOITA et al., 2014).

Considerando a ocorrência de eventos extremos de precipitação acima do percentil 95\% (R95P), a projeção futura se assemelha ao que já vem sendo observado atualmente em estudos como de Silva (2013) e Reis et al. (2018), isto é, aumento do volume de chuva em episódios extremos durante a estação chuvosa do sudeste do Brasil (Figura 6). Somente o RegGFDL indica redução do volume de chuva nos eventos extremos na primavera (Figura $6 j$ ). No inverno, 0 RegGFDL e o RegMPI projetam redução da precipitação durante os eventos extremos, enquanto isso não ocorre no RegHadGEM. O padrão descrito do R95P se assemelha ao do RX5day, que indica a precipitação máxima numa sequência de 5 dias (Figura 7). Em geral, os dias consecutivos muito chuvosos são projetados no verão, com exceção no RegMPI que projeta essa característica na primavera (Figura 7 l).
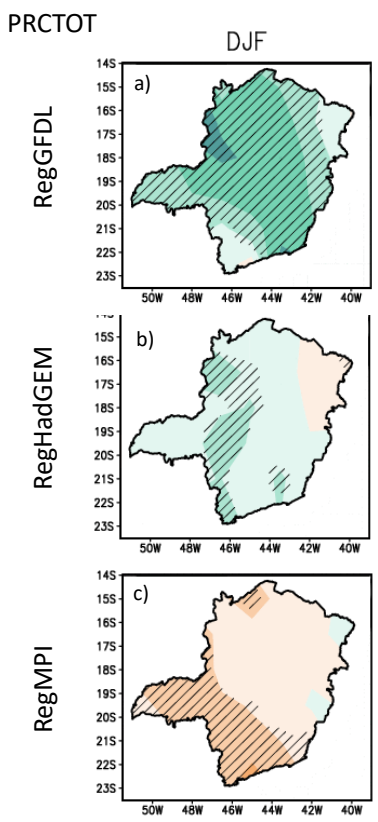
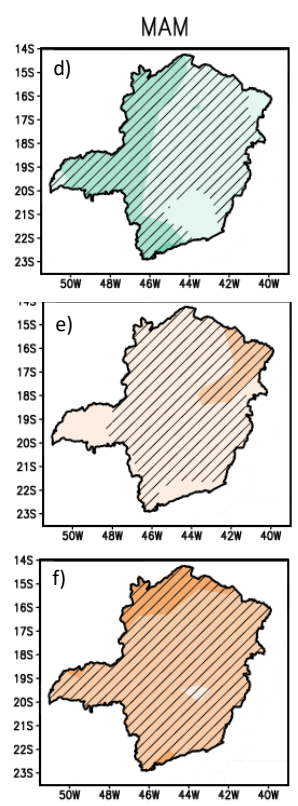
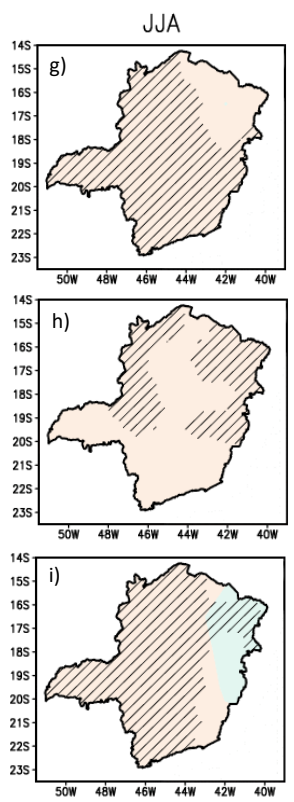
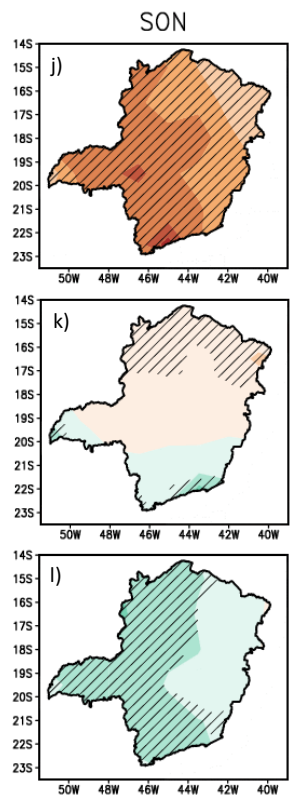

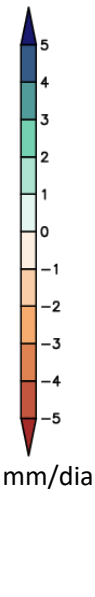

Figura 5 - Projeção sazonal da precipitação (PRCTOT, mm/dia), futuro (2070-2095) menos presente (1980-2005), no Estado de Minas Gerais considerando o cenário RCP8.5. Regiões hachuradas indicam que há significância estatística nas diferenças com a=0,1. 

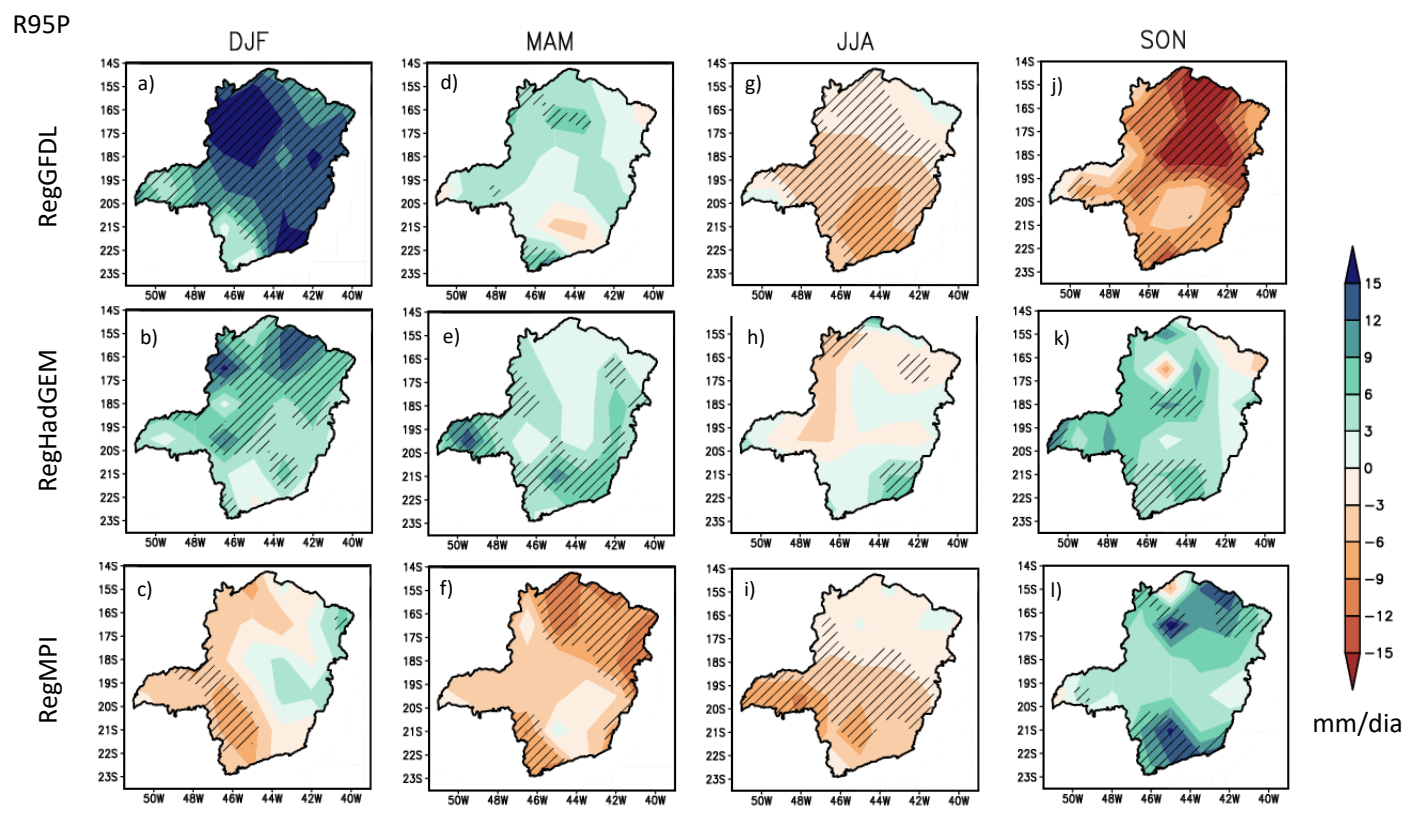

Figura 6 - Projeção sazonal dos extremos de precipitação acima do percentil 95\% (R95P, $\mathrm{mm} / \mathrm{dia}$ ), futuro (2070-2095) menos presente (1980-2005), no Estado de Minas Gerais considerando o cenário RCP8.5. Regiões hachuradas indicam que há significância estatística nas diferenças com $a=0,1$.
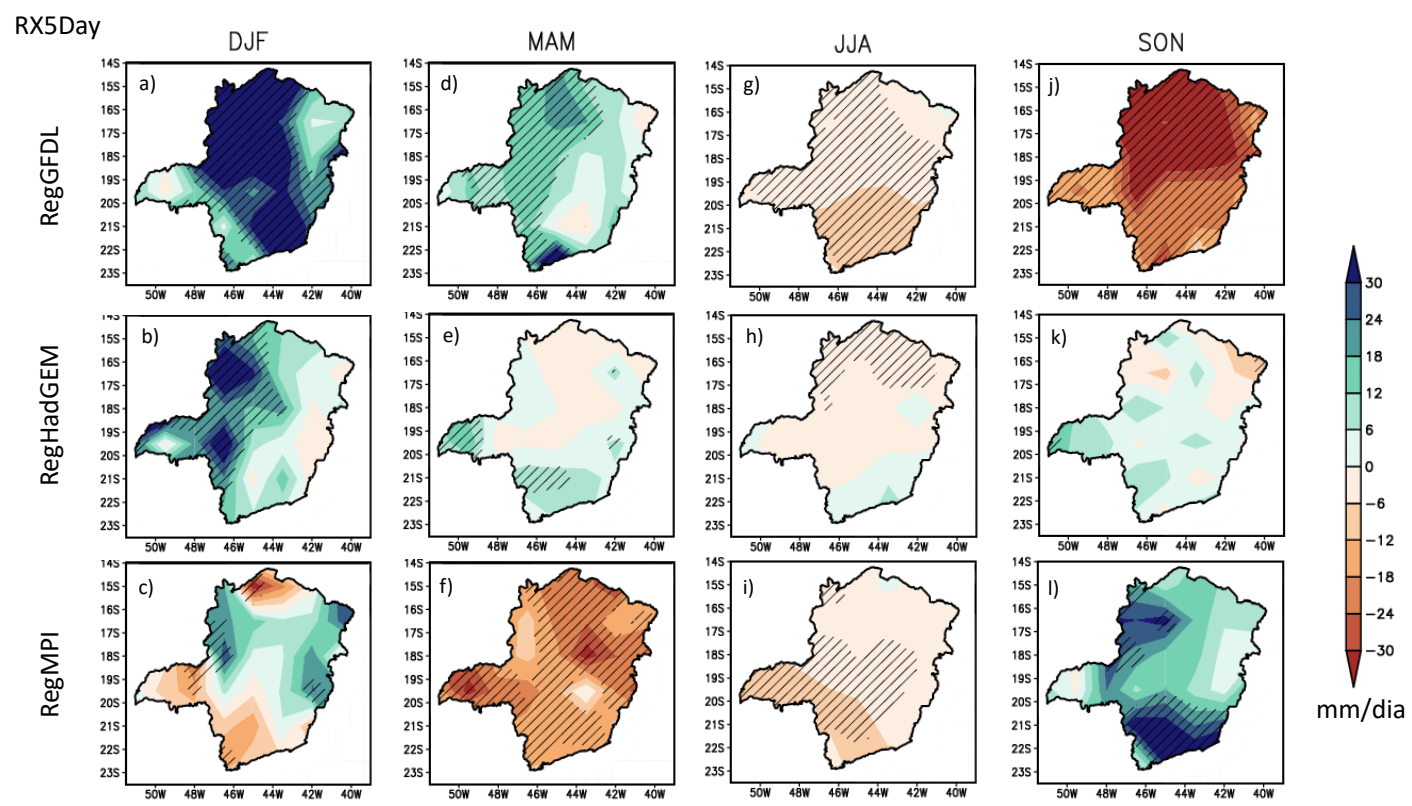

Figura 7 - Projeção sazonal do total de precipitação numa sequência de 5 dias (RX5day, mm/dia), futuro (2070-2095) menos presente (1980-2005), no Estado de Minas Gerais considerando o cenário RCP8.5. Regiões hachuradas indicam que há significância estatística nas diferenças com $a=0,1$. 
As sequências de dias consecutivos úmidos (CWD) são projetadas a diminuir do outono à primavera, quando comparadas ao presente. No verão, não são projetadas mudanças significativas no CWD (Figura 8), enquanto a sua redução ocorre principalmente no outono no RegHadGEM e RegMPI e na primavera no RegGFDL (Figura 8). Por outro lado, as projeções indicam, na maioria das estações do ano, aumento das sequências de dias consecutivos secos (CDD, Figura 9). Essa característica é bem marcada na primavera no RegGFDL e RegHadGEM, mas não no outono no RegGFDL.

CWD
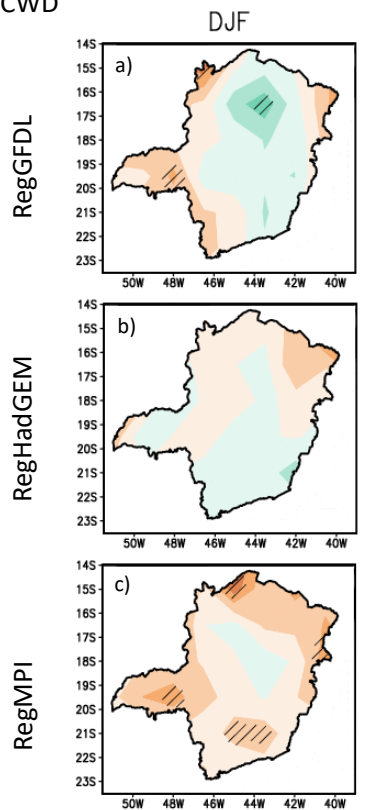
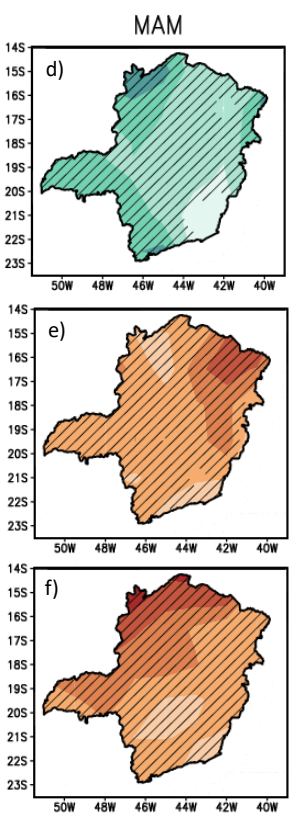
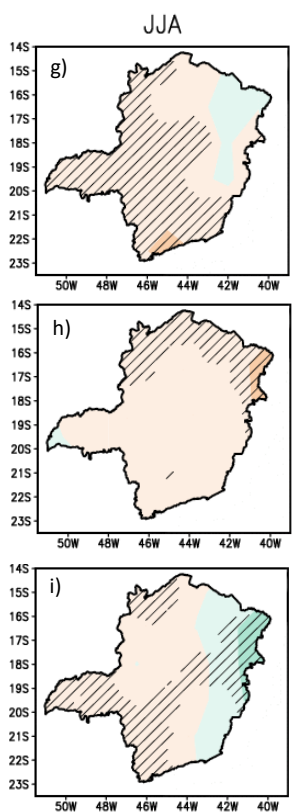
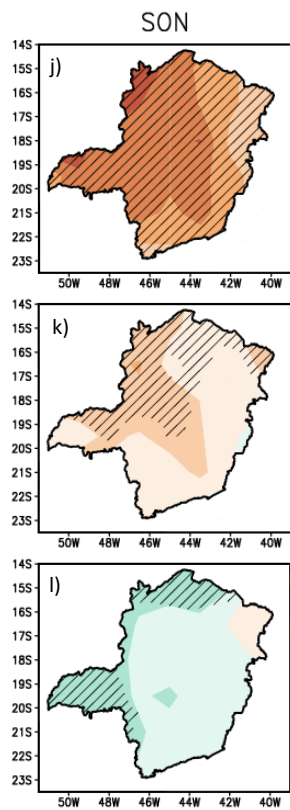

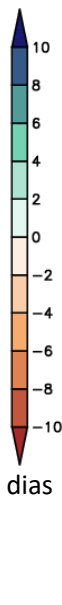

Figura 8 - Projeção sazonal do número de dias consecutivos úmidos (CWD, número de dias), futuro (2070-2095) menos presente (1980-2005), no Estado de Minas Gerais considerando o cenário RCP8.5. Regiões hachuradas indicam que há significância estatística nas diferenças com $a=0,1$. 

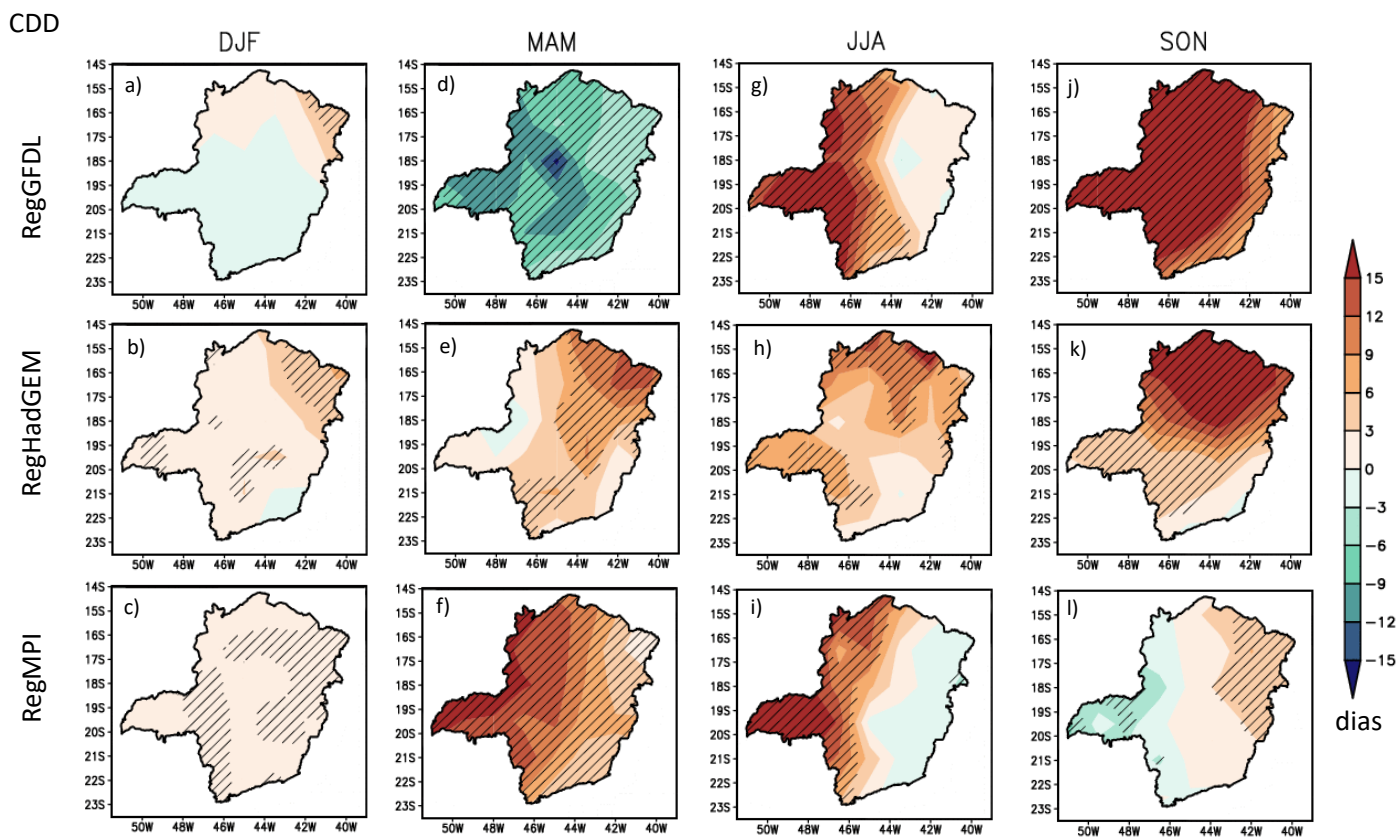

Figura 9 - Projeção sazonal do número de dias consecutivos secos (CDD, número de dias), futuro (2070-2095) menos presente (1980-2005), no Estado de Minas Gerais considerando o cenário RCP8.5. Regiões hachuradas indicam que há significância estatística nas diferenças com $a=0,1$.

\section{CONCLUSÕES}

Este estudo teve como objetivo mostrar as projeções de temperatura do ar e precipitação em MG obtidas com o modelo climático regional RegCM4. É importante enfatizar que as projeções climáticas não são a "verdade absoluta" do mundo no futuro. Elas são indicativos do que pode ocorrer com base em diferentes cenários. Também foi objetivo do estudo mostrar que projeções com um mesmo modelo, mas usando diferentes condições iniciais e de fronteira, bem como esquemas de parametrização física, geram resultados diferentes. Portanto, para estudos tanto do clima presente como futuro nos quais se utilizem modelos climáticos regionais, é importante analisar mais de uma simulação/projeção, a fim de avaliar as incertezas relacionadas: (a) às parametrizações prescritas, (b) à variabilidade interna do modelo e (c) ao uso de diferentes modelos climáticos globais utilizados para forçar o regional. Nesse estudo foi mostrado que as três simulações/projeções utilizadas não apresentam padrões de temperatura e precipitação totalmente iguais, daí a importância em se utilizar um conjunto de simulações (e avaliar o valor médio) para se ter um resultado mais robusto.

O presente estudo projeta para 2070-2095: (a) aumento da temperatura do ar em todo o Estado, que pode chegar a $5{ }^{\circ} \mathrm{C}$, (b) aumento do total sazonal da precipitação no verão e redução no inverno, (c) aumento do volume de chuva em eventos extremos de precipitação, exceto no inverno, (d) redução do número de dias úmidos entre o outono e a primavera e (e) aumento do número de dias consecutivos secos em todas as estações do ano. Esse estudo pode 
servir como guia para a tomada de decisões no Estado de MG frente às mudanças climáticas.

\section{AGRADECIMENTOS}

Os autores agradecem ao Abdus Salam International Centre for Theoretical Physics pela disponibilização das projeções climáticas, ao CPC pelas observações de temperatura do ar e precipitação e ao CNPq, CAPES e FAPEMIG pelo auxílio financeiro.

\section{REFERÊNCIAS}

AMBRIZZI, T.; REBOITA, M. S.; DA ROCHA, R. P.; LLOPART, M. The state-ofthe-art and fundamental aspects of Regional Climate Modeling in South America. Annals of the New York Academy of Sciences, especial edition: Climate Science, 2018.

ASSAD, E. D.; PINTO, HILTON S.; ZULLO JUNIOR, J.; ÁVILA, A. M. H. Impacto das mudanças climáticas no zoneamento agroclimático do café no Brasil. Pesquisa Agropecuária Brasileira, v. 39, n. 11, p. 1057-1064, 2004.

ÁVILA, L. F.; MELLO, C. R.; YANAGI, S. N. M.; SACRAMENTO NETO, O. B. Tendências de temperaturas mínimas e máximas do ar no Estado de Minas Gerais. Pesquisa Agropecuária Brasileira, v. 49, n. 4, p. 247-256, 2014.

CAMPOS, B.; REBOITA, M. S.; CARVALHO, V. S. B.; DIAS, C. Circulações Locais Induzidas pela Topografia no Vale do Paraíba e na Serra da Mantiqueira: um estudo de caso para o período entre os dias 16 e 22 de agosto de 2010. Revista Brasileira de Geografia Física, v. 9, n. 3, p. 753-765, 2016.

CHEN, M.; SHI, W.; XIE, P.; SILVA, V. B. S.; KOUSKY, V. E.; HIGGINS, R. W.; JANOWIAK, J. E. Assessing objective techniques for gauge-based analyses of global daily precipitation. Journal of Geophysical Research, v. 113, D04110, 2008.

COELHO, C. A. S.; OlIVEIRA, C. P.; AMBRIZZI, T.; REBOITA, M. S.; CARPENEDO, C. B. et al. The 2014 southeast Brazil austral summer drought: regional scale mechanisms and teleconnections. Climate Dynamics, v. 46, n. 1112, p. 3737-3752, 2015.

DA ROCHA, R. P.; REBOITA, M. S.; DUTRA, L. M. M.; LLOPART, M.; COPPOLA, E. Interannual variability associated with ENSO: present and future climate projections of RegCM4 for South America-CORDEX domain. Climatic Change, v. 125, p. 95-109, 2014.

DARELA FILHO, J. P.; LAPOLA, D. M.; TORRES, R. R.; LEMOS, M. C. Socioclimatic hotspots in Brazil: how do changes driven by the new set of IPCC climatic projections affect their relevance for policy? Climatic Change, $134, \mathrm{n}$. 34, p. 413-425, 2016.

DICKINSON R. E.; HENDERSON-SELLERS, A.; KENNEDY, P. J. Biosphereatmosphere transfer scheme (BATS) version $1 \mathrm{e}$ as coupled to the NCAR community model. NCAR Tech. Note NCAR/TN-3871STR, p 72, 1993.

DUNNE, J. P.; JOHN, J. G.; ADCROFT, A. J.; GRIFES, S. M.; HALLBERG, R. W.; SHEVLIAKOVA, 
E.; STOUffER, R. J.; COOKE, W.; DUNNE, K. A.; HARRISON, M. J.; KRASTING, J. P.;

MALYSHEV, S. L.; MILLY, P. C. D.; PHILIPPS, P. J.; SENTMAN, L. T.; SAMUELS, B. L.;

SPELMAN, M. J.; WINTON, M.; WITTENBERG, A. T.; ZADEH, N. GFDL'S ESM2 global coupled climate-carbon earth system models. Part I: physical formulation and baseline simulation characteristics. Journal of Climate, v. 25, n. 19, p. 6646-6665, 2012.

EMANUEL, K. A.; ŽIVKOVIĆ-ROTHMAN, M. Development and evaluation of a convection scheme for use in climate models. Journal of the Atmospheric Sciences, v. 56, n. 11, p. 1766-1782, 1999.

FRICH, P.; ALEXANDER, L.; DELLA-MARTA, P.; GLEASON, B.; HAYLOCK, M. ; KLEIN TANK, A.; PETERSON, T. Observed coherent changes in climate extremes during the second half of the twentieth century. Climate Research, v. 19, p. 193-212, 2002.

GETTELMAN, A.; ROOD, R. B. Demystifying climate models: a user guide to earth system models. SpringerOpen. 2016. Disponível:<http://www.springer.

com/us/book/9783662489574>. Acesso: 15 fev 2017.

GIORGETTA, M.; JUNGCLAUS, J.; REICK, C.; LEGUTKE， S.; BROVKIN, V.; CRUEGER, T.; ESCH, M.; FIEG, K.; GLUSHAK, K.; GAYLER, V.; HAAKH HOLLWEG, H.-D.; KINNE, S.; KORNBLUEH, L.; MATEI, D.; MAURITSEN, T.; MIKOLAJEWICZ, U.; MÜLLER, W.; NOTZ, D.; RADDATZ, T.; RAST, S.; ROECKNER, E.; SALZMANN, M.; SCHMIDT, H.; SCHNUR, R.; SEGSCHNEIDER, J.; SIX, K.; STOCKHAUSE, M.; WEGNER, J.; WIDMANN, H.; WIENERS, K.-H.; CLAUSSEN, M.; MAROTZKE, J.; STEVENS, B. CMIP5 simulations of the Max Planck Institute for Meteorology (MPI-M) based on the MPI-ESM-LR model: the rcp85 experiment, served by ESGF. World Data Cent Clim. doi:10.1594/WDCC/CMIP5.MXELr8, 2012.

GIORGI, F. Uncertainties in climate change predictions, from the global to the regional scale. EPJ Web Conf., v. 9, p. 115-129, 2010.

GIORGI, F., COPPOLA, E.; RAFFAELE, F.; DIRO, G. T.; FUENTES-FRANCO, R.; GIULIANI, G.; MAMGAIN, A.; LLOPART, M. P.; MARIOTTI, L.; TORMA, C. Changes in extremes and hydroclimatic regimes in the CREMA ensemble projections. Climatic Change, v. 125, p. 39-51, 2014.

GIORGI, F., JONES, C.; ASRAR, G. Addressing climate information needs at the regional level: the CORDEX framework. World Meteorol. Org. Bull., v. 58, p. 175-183, 2009.

GIORGI, F.; MEARNS, L. O. Introduction to special section: regional climate modeling revisited. Journal of Geophysical Research: Atmospheres, v. 104, p. 6335-6352, 1999.

GRELL, G. A. Prognostic evaluation of assumptions used by cumulus parameterizations. Monthly Weather Review, v. 121, p. 764-787, 1993.

HAYLOCK, M. R.; PETERSON, T. C.; ALVES, L. M.; AMBRIZZI, T.; ANUNCIACAO, T.; BAEZ, J.; BARROS, V. R.; BERLATO, M. A.; BIDEGAIN, M.; CORONEL, G. et al. Trends in total and extreme South American rainfall 1960-2000 and links with sea surface temperature. Journal of Climate, v. 19, p. 1490-1512, 2006. 
IPCC, 2007: Climate Change 2007: The Physical Science Basis. Contribution of Working Group I to the Fourth Assessment Report of the Intergovernmental Panel on Climate Change [Solomon, S., D. Qin, M. Manning, Z. Chen, M. Marquis, K.B. Averyt, M.Tignor and H.L. Miller (eds.)]. Cambridge University Press, Cambridge, United Kingdom and New York, NY, USA. Disponível em: <https://www.ipcc.ch/publications_and_data/ar4/wg1/en/faq-1-1.html>. Acesso: 12 jul 2018.

IPCC, 2012. Managing the Risks of Extreme Events and Disasters to Advance Climate Change Adaptation. A Special Report of Working Groups I and II of the Intergovernmental Panel on Climate Change, Cambridge University Press, Cambridge, UK, and New York, NY, USA,

$582 \mathrm{pp}$.

IPCC, 2013: Climate Change 2013: The Physical Science Basis. Contribution of Working Group I to the Fifth Assessment Report of the Intergovernmental Panel on Climate Change [Stocker, T.F., D. Qin, G.-K. Plattner, M. Tignor, S.K. Allen, J. Boschung, A. Nauels, Y. Xia, V. Bex and P.M. Midgley (eds.)]. Cambridge University Press, Cambridge, United Kingdom and New York, NY, USA, 1535 pp, doi: $10.1017 /$ CBO9781107415324.

IPCC, 2013. Figure 10.21. Disponível: <http://www.ipcc.ch/report/graphics/images/Assessment\%20Reports/AR5\%20\%20WG1/Chapter\%2010/Fig10-21.jpg>. Acesso: 02 jul 2018.

IWABE, C. M. N.; REBOITA, M. S.; CAMARGO, R. Estudo de caso de uma situação atmosférica entre 12 e 19 de setembro de 2008, com algumas características semelhantes ao evento Catarina. Revista Brasileira de Meteorologia, v. 26, n. 1, p. 67-84, 2011.

JONES, C. D.; HUGHES, J. K.; BELLOUIN, N.; HARDIMAN, S. C.; JONES, G. S.; KNIGHT, J.;

LIDDICOAT, S.; O'CONNOR, F. M.; ANDRES, R. J.; BELL, C.; BOO, K.-O.; BOZZO,

A.; BUTCHART, N.; CADULE, P.; CORBIN, K. D. ; DOUTRIAUX-BOUCHER, M.;

FRIEDLINGSTEIN, P; GORNALL, J.; GRAY, L.; HALLORAN, P. R.; HURTT, G.; INGRAM,

W. J.; LAMARQUE, J.-F.; LAW, R. M.; MEINSHAUSEN, M.; OSPREY, S.; PALIN, E. J.;

PARSONS CHINI, L.; RADDATZ, T. SANDERSON, M. G.; SELLAR, A. A.; SCHURER,

A.; VALDES, P.; WOOD, N.; WOODWARD, S.; YOSHIOKA, M.; ZERROUKAT, M. The HadGEM2-ES implementation of CMIP5 centennial simulations. Geosci Model Dev, v. 4, p. 543-570, 2011.

LSPA-IBGE, 2017.2 Disponível em:<https://biblioteca.ibge.gov.br/visualizacao/periodicos/6/Ispa_pesq_2017_d ez.pdf>. Acesso: 24 jun 2018.

LATIF, M. Uncertainty in climate change projections. Journal of Geochemical Exploration, v. 110, p. 1-7, 2011. 
LLOPART, M.; COPPOLA, E.; GIORGI, F.; DA ROCHA, R. P.; CUADRA, S. V. Climate change impact on precipitation for the Amazon and La Plata basins. Climatic Change, v. 125, p. 111-125, 2014.

MARENGO, J. A.; NOBRE, C. A.; TOMASELLA, J.; OYAMA, M. D.; OLIVEIRA, G. S.; OLIVEIRA, R.; CAMARGO, H.; ALVES, L. M.; BROWN, I. F. The drought of Amazonia in 2005. Journal of Climate, v. 21, p. 495-516, 2008.

MARENGO, J. A.; TOMASELLA, J.; ALVES, L. M.; SOARES, W. R.; RODRIGUEZ, D. A. The drought of 2010 in the context of historical droughts in the Amazon region. Geophysical Research Letters, v. 38, p. 1-5, 2011.

McTAGGART-COWAN, R.; BOSART, L.; DAVIS, C. A.; ATALLAH, E. H.; GYAKUM, J. R.; EMANUEL, K. A. Analysis of Hurricane Catarina (2004). Monthly Weather Review, v. 134, p. 3029-3053, 2006.

NATIVIDADE, U. A.; GARCIA, S. R.; TORRES, R. R. Tendência dos Índices de Extremos Climáticos Observados e Projetados no Estado de Minas Gerais. Revista Brasileira de Meteorologia, v. 32, n. 4, p. 600-614, 2017.

OLIVEIRA, D. M., REBOITA, M. S., DA ROCHA R. P. A influência da topografia da região sul de Minas Gerais nas variáveis atmosféricas simuladas com o RegCM4. Revista Brasileira de Geografia Física, v. 11, n. 3, p. 758-772, 2018.

REBOITA, M. S.; AMARO. T. R., SOUZA, M. R. Winds: intensity and power density simulated by RegCM4 over South America in present and future climate. Climate Dynamics, online version, doi 10.1007/s00382-017-3913-5, 2017.

REBOITA, M. S., DA ROCHA, R. P., DIAS, C. G., YNOUE, R. Y. Climate projections for South America: RegCM3 driven by HadCM3 and ECHAM5. Advances in Meteorology, p. 1-17, 2014.

REBOITA, M. S.; RODRIgUeS, M.; SILVA, F. F.; ALVES, M. A. Aspectos Climáticos do Estado de Minas Gerais. Revista Brasileira de Climatologia, v. 17, p. 206-226, 2015.

REIS, A. L., SILVA, M. S.; REGIS, M. V.; SILVEIRA, W. W.; SOUZA, A. C.; REBOITA, M. S.; CARVALHO, V. S. B. Climatology and extreme rainfall events in the state of Minas Gerais. Revista Brasileira de Geografia Física, v.11, n. 2, p. 652-660, 2018.

SALVIANO, M. F.; GROPPO, J. D.; PELLEGRINO, G. Q. Análise de Tendências em Dados de Precipitação e Temperatura no Brasil. Revista Brasileira de Meteorologia, v. 31, n. 1, p. 64-73, 2016.

SANTOS, D. F.; MARTINS, F. B.; TORRES, R. R. Impacts of climate projections on water balance and implications on olive crop in Minas Gerais. Revista Brasileira de Engenharia Agrícola e Ambiental. v. 21, n. 2, p. 77-82, 2017.

SILLMANN, J.; KHARIN, V. V.; ZWIERS, F. W.; ZHANG, X.; BRONAUGH, D. Climate extremes indices in the CMIP5 multi-model ensemble. Part 1: Model evaluation in the present climate. Journal of Geophysical Research: Atmospheres, v. 118, n. 4, p. 1716-1733, 2013a.

SILLMANN, J.; KHARIN, V. V.; ZWIERS, F. W.; ZHANG, X.; BRONAUGH, D. Climate extremes indices in the CMIP5 multi-model ensemble. Part 2: Future climate projections. Journal of Geophysical Research: Atmospheres, v. 118, n. 6, p. 2473-2493, 2013b. 
SILVA, E. D. Estudo da precipitação no estado de Minas Gerais - MG. Dissertação (Mestrado em Meio Ambiente e recursos Hídricos) - Universidade Federal de Itajubá, Itajubá, 70f. 2013.

SILVA, E. D.; REBOITA, M. S. Estudo da Precipitação no Estado de Minas Gerais - MG. Revista Brasileira de Climatologia, v. 13, p. 120-136, 2013.

TAWFK, A. B.; STEINER, A. L. The role of soil ice in land-atmosphere coupling over the United States: a soil moisture-precipitation winter feedback mechanism Journal of Geophysical Research, v. 116, D02113, 2011.

QUINTÃO, A. F.; BRITO, I.; OLIVEIRA, S.; MADUREIRA, A. P.; CONFALONIERI, U. Social, Environmental, and Health Vulnerability to Climate Change: The Case of the Municipalities of Minas Gerais, Brazil. Journal of Environmental and Public Health, Volume 2017, Article ID 2821343, 2017.

TRIOLA, M. F. Introdução à estatística. 10 a ed. Rio de Janeiro: LTC, 2008.

VAN VUUREN, D. P.; EDMONDS, J.; KAINUMA, M.; RIAHI, K.; THOMSON, A.; HIBBARD, K.; HURTT, G. C.; KRAM, T.; KREY, V.; LAMARQUE, J. F.; MASUI, T.; MEINSHAUSEN, M.; NAKICENOVIC, N.; SMITH, S. J.; ROSE, S. K. The representative concentration pathways: an overview. Climatic Change, v. 109, p. 5-31, 2011.

YNOUE, R. Y.; REBOITA M. S.; AMBRIZZI, T.; SILVA, G. A. M. Meteorologia: Noções Básicas. Oficina de Textos, São Paulo, 2017 